\title{
A Guide to Promote Elderly Resilience: A Perspective from Thai Context
}

\author{
Sonthaya Maneerat ${ }^{1, *}$, Sangarun Isaramalai ${ }^{2}$, Suthicharat Jantiya ${ }^{3}$ \\ ${ }^{1}$ Boromrajonnani College of Nursing Nopparat Vajira \\ (Bangkok, Thailand) \\ ${ }^{2}$ Faculty of Nursing, Prince of Songkla University \\ (Songkla, Thailand) \\ ${ }^{31}$ Boromrajonnani College of Nursing Nopparat Vajira \\ (Bangkok, Thailand) \\ ${ }^{*}$ Corresponding author's email: sonthaya [AT] bcnnv,ac,th
}

\begin{abstract}
Resilience is a positive adaptation after experienced with a crisis situation and quickly return to normal life. The guide to promote elderly was wrote base on the study of Maneerat, et al (2015), which focused on development of the resilience scale for elderly in Thai context. The result yielded the conceptual structure of resilience and the quality of specific scale to assess resilience among Thai elderly. The aims of article was discussion about guideline to promote resilience in elderly within Thai context. 5 ways to promote resilience to elderly consisting of 1) making a connection, 2) enhancing a confident to live 3) helping to seek social support 4) living with spiritual security and 5) enhancing an ability to de-stress and manage problems. The introduction will be discussed some background behind the concept and significance of resilience in Thai elderly. The main body of this article is a practical guide based on five ways to build elderly resilience from Thai perspective. The guide will help health care provider to promote resilience among elderly.
\end{abstract}

Keywords - Thai elderly, resilience, promotion

\section{INTRODUCTION}

Nowadays, the rapid increasing in the number and the proportion of elderly population is becoming a worldwide phenomenon. The elderly population of 60 years and older is the fastest growing in the world among all age groups [1]. The growing elderly population is no longer a concern only for rich countries but is also putting increasing pressure on poorer regions in the developing world [2]. In Thailand, like most developed countries, the number of older persons (defined as aged 60 and over) in Thailand has grown rapidly and will continue to do so in future decades. Since 1960 the number of older people in the Thai population has increased seven-fold from approximately 1.5 million to 10.7 million by 2015 or $16 \%$ of the total population. Future population ageing will occur even more rapidly with the number of older persons projected to increase to over 20 million by 2035, at which point they will constitute over $30 \%$ of the population [3]. Aging phenomenon also has a major effect at an individual level. Getting older, elderly go through the inevitable decline of physical function which, in turn, influences their mental health. These health problems impede the elderly abilities to care for themselves, deteriorate their mental health, and have an adverse effect on their resilience [4]. Health professionals should play roles in cultivating and nurturing resilience, which will ameliorate the negative effects of other health deterioration, in this population. Mental health problems are generally accepted as a major health issue in the elderly. One of the most common mental health issues in this age group is depression. Depression often occurs in elderly patients who suffer with other medical conditions and disabilities. It can occur in the elderly anytime, but it is not a normal part of aging. Depression affects about $1-5 \%$ of the general elderly population, $13.5 \%$ in elderly who require home healthcare, and $11.5 \%$ in older hospital patients [5]. Only a small percentage of the elderly with depression actually receives assistance and treatment [6]. Common factors related to depression among the elderly, i.e., trauma from major life's adversity including loss of spouse, retirement, living with a chronic illness or economic problem, and especially a lack of support system. The study of Soonthornchaiya )2004( [7]. supported that depression in Thai elderly was induced by three causes, i.e., 1( loss 2( negative thinking of self, environment, and future life and 3( rule of "karma" (sin) in Buddhism. However, some studies show that there are strong association between greater resilience and less depressive symptomatology [8]. Moreover, high resilience has also been significantly associated with positive outcomes, including successful aging, lower depression, and longevity [9]. Fostering the use of interventions to promote resilience in older 
adults as a means of preventing and managing depressive symptoms in this population including interventions to enhance resilience within this population are needed.

\section{CONTEXT RELATED TO THAI ELDERLY}

In Thailand, the definition of an older person means a person of 60 years of age and older [10]. The number of older persons in Thailand has grown rapidly and will continue to do so in future decades. Since 1960 the number of older people in the Thai population has increased seven-fold from approximately 1.5 million to 10.7 million by 2015 or $16 \%$ of the total population. By the year 2027, the number of Thai elderly is expected to reach 14 million, or $20 \%$ out of 70 million of the total population [11]. Future population ageing will occur even more rapidly with the number of older persons projected to increase to over 20 million by 2035, at which point they will constitute over $30 \%$ of the population [5]. Thailand has just recently realized this aging phenomenon and thus has fairly shorter time to prepare for the tremendous change, compared to the developed countries as aforementioned. Today, the country is by no means ready to handle the rise of aging population or adjust to respond their needs such as health care and social services(. In order to better understand the lifestyles and needs of the Thai elderly, the following section sheds light on the demographic, sources of support, educational and economic aid, and value and expectation of the target population. The demographic of Thai older adult composition was $44.25 \%$ male and $55.75 \%$ female [12] $63.5 \%$ was married while the other $41.9 \%$ included single widow, separate and divorcé. In Past Thai education law required every Thai to have the minimum of primary education, therefore, the survey found that the majority of Thai elderly had primary or less than primary level education $) 75.7 \%$, and $11.0 \%$ was reported to be illiterate [13].

\section{RESILIENCE IN THAI ELDERLY}

Resilience is not a trait that people either have or do not have. It involves behaviors, thoughts and actions that can be learned and developed in anyone. Resilience is the process of adapting well in the face of adversity, trauma, tragedy, threats or significant sources of stress such as family and relationship problems, serious health problems or workplace and financial stressors. It means "bouncing back" from difficult experiences [14]. Resilience commonly demonstrate when people faced with life suffering. The suffering can be the precipitating that produces mental health problems. As we know, when old aged, individuals will face with numerous challenges that threaten their well-being. Resilience reflects their ability in self-management on the negative effect of adverse events on health and well-being. Several studies indicated that potentially traumatic events in adult life are likely to be related with current impairment of mental health problems.

\section{BUILDING RESILIENCE IN ELDERLY PEOPLE}

From the result study of Maneerat et al. (2015) [15], the five domains of conceptual structure related to resilience in Thai context were applied to building resilience. The ways concluded one inner strength, two external supports, and two ability as follows:

1. Make connection: Having a good relationships with close family members, friends or others are very important for building resilience. The significant of this way was enhancing an ability of older adults to join with people. The attribute represented social characteristics such as enjoy socializing, having opportunity to socialize, having a sense of humor during friendship, etc. The family and social networks play important role in building greater resilience. Furthermore, secure interpersonal relationships provide an important source of emotional support. Moreover, Fiori, Antonucci, \& Cortina (2006) [16] also agree that an active social network of family and friends can promote healthy aging through a variety of mechanisms including tangible and emotional support. They need to welcome new friendships and love to join with others. The implication of this way is making a good relationships with others within a positive attitudes and characteristics. Accepting help and support from those who have a good relationship will help them to build resilience. Being active in elderly groups, religious and spiritual group, or any activities are good examples for building resilience among elderly in Thai context.

2) Enhancing a confident to live. Facing with suffering in life, all human need to survive and go back to the normal life. The successful coping despite adversity need to have positive view of self, especially the sense of mental strength, for example: value of life, patience, confidence, satisfied with life, and pride in self - all of which refer to an individual's feeling and concepts about self and abilities to deal with life's challenges. The healthier mind refer to the greater resilience. The elderly who have the sense of mental strength should have high ability to deal with crisis. The emotionally healthy are often in control of their emotions and their behaviors. They are able to handle life's inevitable challenges, build strong relationships, and lead productive and fulfilling lives. When bad things happen, they're able to bounce back and move on. Having a purpose in life are the most one important of psychological building blocks of resilience [17]. It's also associated with emotional health. So, keeping things in perspective and maintain a hopeful outlook even when experience very painful events can help them look at the situation in a broader context and keep a long-term perspective. Furthermore, optimistic and positive outlook can enable the elderly to see the good things in life 
and keep going even in the hardest times, such as, use their lesson learn from positive life history to show that life moves on after bad events.

3) Helping to find social support. Social support is a factor that play a significant role in individual resilience as the ability to recover from hardship and move forward in a positive, adaptive way. Having good social relationships is clearly predictors to individual resilience particularly in life of aging. It's not surprising that social relationships also matter when it comes to resiliency, in part because they can help them to feel less stress when faced with suffering. Furthermore, an emotional support is an important kind of social support that see as a source of affection, comfort, and companionship. Also as mentioned by Shaw et al. (2007) [18], social networks are considered to be an important determinant of the quality of life (QOL) of the elderly, notably by allowing them to deal with stressful environments or difficult life experiences. In addition, social support from the wider community also serves as a building block for resilience [19-21].

4) Living with spiritual security. The component of living with spiritual security includes having a chance to pray for good life, engaging in religious practice regularly, relying on spiritual beliefs, and using religious doctrine to solve problems. Generally, spiritual belief is viewed as divine powers that assure the elderly that they are not alone. Prayer is seen as a means to reach for help during difficult times. This component seems to be congruent with the attributes related to resilience, i.e., personal beliefs and values [22], having a strong faith, belief in a divine power, and prayer, religiosity, spirituality, and faith, culture-based health beliefs, personal support and other kinds of support, and feeling connected [23-27]. Furthermore, religious or spiritual belief has been implicated as an external component that can aid resilience by instilling a sense of hope in some individuals. Moreover, additional evidence supports resilience as an ability to successfully adapt using strong faith and spiritual upbringing of the elderly widowers following the death of a spouse.

5) Enhancing an ability to de-stress and manage problems. The attributes of this strategy were positive self-talk, learning from previous experiences, relieving stress by self, and sharing suffered feelings with a trusted person. It reflects the capacity of an individual to cope during difficulty which is central to their resilience. Resilient individuals are more likely to feel confident that they can cope successfully with adversity, and often employ a range of problem-solving and emotion-focused strategies.

\section{CONCLUSION}

The guide to building elderly resilience related to Thai context is a specific activities. The elderly resilience promotion consisting of five ways by helping them to 1) make connection, promote a confident to live, 3) find social support, 4) live with spiritual security and 5) able to de-stress and manages problems. Various activities can be applied to program. The intervention such as a group weekly meeting with education and social group activity, exercise, discussion, and skill training should be done.

\section{REFERENCES}

[1] World Health Organization [WHO], 2018(. Retrieved Oct, 1, 2018 from https://www.who.int/ageing/en/

[2] Eugen Tomiuc. (2002). UN: World Population Aging Rapidly In Developing Countries Retrieved Oct, 1,2018 from www.rferl.org/a/1099361.html.

[3] John Knodel J, Teerawichitchainan, B, Prachuabmoh V.and Pothisiri W.(2015). The Situation of Thailand's Older Population: an update based on the 2014 Survey of Older Persons in Thailand: Bangkok, Thailand.

[4] Talsma, )1995(. Evaluation of a theoretical model of resilience and select predictors of resilience in a sample of community-based elderly. Doctoral dissertation. University of Michigan.

[5] Centers for Disease Control and Prevention. (2017). Depression is Not a Normal Part of Growing Older. Division of Population Health, updates January 31, 2017, retrieved from: https://www.cdc.gov/aging/mentalhealth/depression.htm

[6] National Health Association. (2009). Depression in older adult. Retrieved October, 18,2010 from http://www.nmha.org/go/information/get-info

[7] Soonthornchaiya, R. )2004(. The concept of depression and intervention: Thai elderly experienced in USA. The Journal of Psychiatric Nursing and mental Health, 18)1(, 10-18.

[8] Wermelinger Ávila MP, Lucchetti AL, \&Lucchetti G. (2017). Association between depression and resilience in older adults: a systematic review and meta-analysis. Int J Geriatr Psychiatry. 32(3):237-246.

[9] Stephanie at all. (2016).The impact of resilience among older adults. Geriatric Nursing 37:266-272. 
[10] Knodel, J., \& Chayovan, N. )2009(. Older Persons in Thailand: A Demographic, Social and Economic Profile. Aging International, 33, 3-14.

[11] Prasartkul P, et al. (2016). Centenarian Project_Draft FinalReport. Retrieved from http://knowledgefarm.in.th/wpcontent/uploads/

[12] Department of Provincial Administration. (2017). Statistic of elderly in Thailand Retrieved from http://www.dop.go.th/th/know/1

[13] College of Population Studies, Chulalongkorn University. (2016)

[14] American Psychology Association https://www.apa.org/helpcenter/road-resilience.aspx

[15] Maneerat S., Isaramalai S., Boonyasopun U. (2011). A Conceptual Structure of resilience among Thai Elderly. International Journal of Behavioral Science. 6(1): 1-17.

[16] Fiori KL, Antonucci TC, \& Cortina KS. (2006). Social network typologies and mental health among older adults. J Gerontol B Psychol Sci Soc Sci, 61(1):P25-32.

[17] Rutten BPF, Hammels C, Geschwind N, Menne-Lothmann C, Pishva E, et al. (2013). Acta Psychiatr Scand. Resilience in mental health: linking psychological and neurobiological perspectives; 128(1): 3-20

[18] Bosworth HB, Schaie KW. (1997).The relationship of social environment, social networks, and health outcomes in the Seattle Longitudinal Study: Two analytical approaches. J Gerontol Ser B Psychol Sci Soc Sci; 52(5):197205.

[19] Greff, Vansteenwegen \& Ide. (2006). Resiliency in Families with a Member with a Psychological Disorder. American Journal of Family Therapy; 34(4):285-300 •

[20] Luthans F, Vogelgesang Gretchen R, \& Lester P, (2006). Developing the Psychological Capital of Resilience. Human Resource Development Review; 5(1):25-44.

[21] Masten AS, \& M-G.J. REED M-G.J. (2002). Resilience in development. In Handbook of Positive Psychology. C.R. Snyder \& S.J. Lopez, Eds.: 74-88. Oxford University Press. London.

[22] Polk, L.V. )1997(. Toward a middle range theory of resilience. Advance in Nursing Science, 19, 1-13.

[23] Crummy, D.B. (2002). Resilience: The Lived Experience of Elderly Widowers Following the Death of a Spouse. Unpublished Doctoral Dissertation, University of San Diego.

[24] Ong, A.D., \& Bergeman, C.S. )2004(. Resilience and adaptation to stress in later life: empirical perspectives and conceptual implication. Ageing International, 29, 219 - 246.

[25] Connor, K.M., \& Davidson, J.R. )2003(. Development of a new Resilience Scale: The Connor Davidson Resilience Scale )CD-RIS(. Depression and Anxiety, 18, 76-82.

[26] Felten, B.S. )2000(. Resilience in a multicultural sample of community-dwelling women older than age 85. Clinical Nursing Research, 9, 102-123.

[27] Takviriyanun, N. )2008(. Development and testing of the Resilience Factors Scale for Thai adolescents. Nursing and Health Sciences, 10, 203-208 